\title{
Performance Assessment of Pareto and Non-Pareto Approaches for the Optimal Allocation of DG and DSTATCOM in the Distribution System
}

\author{
Khalid IBRAHIM* ${ }^{*}$ Reza SIRJANI, Hussain SHAREEF
}

\begin{abstract}
This paper proposes a Differential Evolution (DE) optimization algorithm and a Pareto-frontier Multi-Objective Differential Evolution (MODE) optimization algorithm for the optimal allocation of Distributed Generation (DG) and Distribution Static Compensator (DSTATCOM) in a radial distribution system. It considers the minimization of active power dissipation, voltage drop and the annual cost as the objectives of this optimization problem. The proposed techniques are tested on an IEEE 33 bus radial distribution system. To compare the performance of the MODE and DE, the weighted sum approach is carried out. This helps to select one solution from the Pareto front of the MODE. Case studies show that the allocation of both DG and DSTATCOM results in a noticeable reduction of system losses, voltage drop and annual cost. Comparative studies also show that the global convergence characteristics of MODE are better than several other optimization algorithms.
\end{abstract}

Keywords: differential evolution; distribution static compensator; distribution system distributed generation; multi-objective differential evolution

\section{INTRODUCTION}

Due to rapid population growth and industrialization, electrical distribution system experiences a huge increment in the load, consequently leading serious problems such as voltage instability, poor power quality and inefficient energy management [1].

Information and communications technology (ICT) solutions have recently been applied for increasing energy efficiency in the modern power grids. For instance, the flow of energy and work such as communication, sensing and computing tasks in computer servers, in a network of intermittent sources of energy, is modelled as Energy Packet Network (EPN) [2]. This model represents the intermittent arrival of energy, its storage and the intermittent use of energy by information and communications technology [3]. Many attempts have been made to optimize EPNs and improve their performance with energy harvesting [2-5].

On the other hand, installing additional active/reactive power compensators in power system is one of the most popular solutions for power quality improvement and voltage stability enhancement. However, with the improvement of technology and the demand for maximum efficiency from an electrical distribution network, the planning of active/reactive devices such as Distribution Generators (DG) and Distributed Static Synchronous Compensators (DSTATCOM) has turned into a true challenge. Although these devices are incorporated into the grid to enhance the quality of the network, the improper capacity and site of these devices may lead to many problems, such as increasing power losses instead of decreasing them [1].

Recently, various types of optimization methods have been projected to determine the optimum site for DGs and DSTATCOMs in distribution grids, which lead to improvements in the networks characteristics. The methods used to solve this optimization problem can be categorized into different groups, such as analytical and heuristic algorithms or single-and multi-objective techniques. Heuristic algorithms are critical-thinking strategies in which the most fitting solution or partial solution is chosen to utilize relative principles. They are regularly utilized in solving the optimization problem including optimum allocation of the DG and DSTATCOM. In light of the working principles of these methods, the solutions acquired frequently have a tendency to be stuck at a good estimate [6].

In 2013, Injeti et al. determined the best site and size for installing several DGs in small, intermediate and outsized radial distribution grids [7]. In 2014, Roy et al. proposed the combination of teaching-learning based optimization technique with quasi-opposition-based learning to investigate the best placement of one DG to decrease the active power dissipation in the standard 33-, 69- and 118-node grids [8]. Furthermore, in 2015 the same authors combined the opposition-based learning algorithm with another heuristic algorithm called krill herd to get the best site for DGs while considering the deduction of the yearly cost as a target [9]. In the same year, Gupta et al. determined the optimal allocation and size of DSTATCOM under a reconfigured network to lessen the power loss [10]. Moreover, Prabha, D. R., \& Jayabarathi, T. proposed an invasive weed algorithm for determining the optimum allocation to insert several DGs into the distribution grids and their capacities to achieve several goals such as voltage enhancement, alleviation of energy dissipation and energy retrenchment [11]. In addition, E. S., Ali et al. presented the Ant Lion Optimization Algorithm to determine the optimum sites for adding several renewable DGs to the network and to calculate the most suitable size for them to decrease energy dissipation and to enhance voltage stability [12].

Moreover, in 2017 Partha P. Biswas et al. determined the optimum allocation and capacity of several DGs and capacitors in the distribution grid by applying a multiobjective approach for minimizing power dissipation. Both DGs and capacitors are utilized to lessen both real and reactive power dissipation. The method was evaluated with similar previous studies and notable improvement was observed [13]. Mahesh Kumar, et al. determined the optimal positioning and the capacity of DGs for voltagedependent load modules in the radial distribution grid. Single and multiple DGs were used (real, reactive and a combination of them). Likewise, five distinct types of load 
models were utilized. In addition, the load growth for the base and next three years was predicted [14].

In reviewing the literature, it is clear that the heuristic algorithm has attracted more attention in the design and optimization of the distribution system than classical methods; nevertheless, most of the researchers used the aggregation approach instead of the Pareto approach. In addition, the accuracy of the results and the speed of the optimizer have been neglected.

The intention of this study is twofold. First, it is to propose the single and pareto-frontier multi- objective version of differential evolution optimization techniques to investigate the optimum allocation and sizing of the DG and DSTATCOM to reduce power dissipation, voltage drop and annual cost. Furthermore, the second objective is to compare the results of the pareto-frontier Multi-Objective Differential Evolution (MODE) optimizer with the singleobjective optimizer Differential Evolution (DE).

The contributions of present research regarding the existing researches can be highlighted as below:

- The application of Differential Evolution optimization algorithm for the optimal allocation of DG and DSTATCOM in the distribution system is presented for the first time.

- A comprehensive performance assessment of pareto and non-pareto approaches for the optimal placement and sizing of both active and reactive power compensators in power system is made. Single and multi-objective approaches are applied and their optimization characteristics are compared in terms of accuracy and speed.

- The costs of DG and DSTATSOM, which were neglected in most of references, are considered and added to the operational cost. For this reason, the obtained results are more realistic and reliable.

- $\quad$ The problem of optimal allocation of multiple DG and DSTATCOM is solved by considering the new cost function. It was previously solved by neglecting DG and DSTATCOM costs.

\section{PROBLEM FORMULATION}

\subsection{Backward/Forward Sweep Load-Flow Algorithm}

A load flow is performed to obtain the system condition (voltage, current, power loss...etc.) in the steady state. It is important to check if the system is stable and to determine if there is a need to insert compensation devices to the system. Furthermore, it is necessary to plan in advance. Due to the low $X / R$ ratio in the distribution system, the ordinary techniques such as Newton Raphson and Gauss-Seidel cannot converge to obtain the power flow from the distribution system. So as to get the power flow of such grid, the backward forward sweep strategy can be utilized. The backward forward sweep method is an iterative method in which, at every iteration, two calculation stages are performed, namely the backward sweep and the forward sweep [15].

- Backward sweep. In this stage, the load current of every bus of an $N$ bus radial distribution grid is obtained.

- Forward sweep. This stage comes after the backward sweep to obtain the voltage at every bus of the distribution grid as follow.

$$
\vec{V}(n)=\vec{V}(m)-\vec{I}(m, n) \times \vec{Z}(m, n)
$$

where: $m$ and $n$ are the receiving and sending end buses respectively, while $\vec{Z}(m, n)$ represents the impedance of the branch $m n$; Fig. 1 below presents the flowchart of the backward-forward sweep.

To place the DSTATCOM and DG in the radial distribution grid, both the real and the reactive load power at the bus where DSTATCOM and DG are placed will change. Therefore, it is assumed that the DG is only injecting a real power into the network, and it is placed at $i^{\text {th }}$ bus according to the following equation:

$P_{i}=P_{i}-P_{\mathrm{DG}, i}$

In the case of the DSTATCOM, the reactive power is changed by:

$Q_{i}=Q_{i}-Q_{\text {DSTATCOM }, i}$

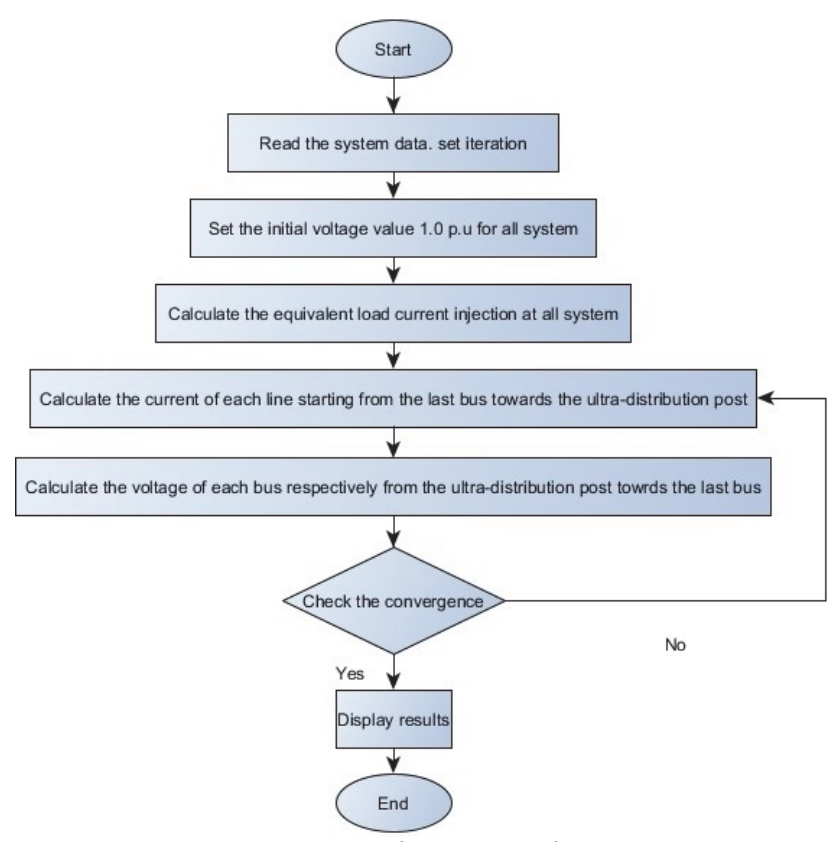

Figure 1 Backward-forward sweep flowchart.

\subsection{Optimization Formulation}

The problem of the optimum size and place of the DSTATCOM and DG can be expressed as a single objective optimization problem by giving each objective function a weight factor. Therefore, the summation of the weight factors should equal one. This problem aims to minimize the summation of the scaled objective functions. Moreover, it can be expressed as a multi-objective optimization problem. Here, the solution aims to minimize the vector of the objective functions, which consist of the real power dissipation in the grid, the voltage deviation and the annual cost simultaneously. The single objective optimization functions can be expressed as:

Minimizing $F=\sum_{i=1}^{m} k_{i} \times f_{i}$ 
where: $k_{i}$ is the weight that is given to the $i^{\text {th }}$ objective function $f_{i}$ to decide its corresponding importance. $k_{i}$, is decided according to priority of the operation. In this work 0.5 for the power loss, 0.4 for the voltage deviation, and 0.1 for the cost is selected according to reference [16].

On the other hand, multi-objective optimization problem can be stated as:

$$
F=\left[\begin{array}{llll}
f_{1} & f_{2} & \cdots & f_{n}
\end{array}\right]
$$

where: $n$ denotes the number of goals to be optimized. In this case, the objective functions will be minimized separately.

\subsubsection{Objectives}

As mentioned earlier, three objective functions are considered to be optimized. These objectives are the reduction of the total active power dissipation, decrease of the voltage deviation and minimization of the yearly cost. For this minimization problem, first each objective function is normalized by dividing it by its base. These functions are explained below in the following equations. The weighted vector objective function is shown below:

$$
F=k_{1} \times f_{1}+k_{2} \times f_{2}+k_{3} \times f_{3}
$$

\section{- Active power losses in the system $\left(f_{1}\right)$}

In fact, about $13 \%$ of total power losses occur in the distribution system [17]. Therefore, the first objective of this study is to minimize the active power losses in the radial distribution grid as described in Eq. (7).

$$
f_{1}=\frac{\sum_{i=1}^{n b} P_{\text {Loss }, i}}{P_{\text {Loss,base }}}
$$

where $P_{\text {loss }, i}$ is the active power dissipation in branch number $i$ in $\mathrm{kW}$. $P_{\text {loss,base }}$ is the base value for the active power dissipation in $\mathrm{kW} . n b$ is the total number of the branches.

\section{- Voltage deviation $\left(f_{2}\right)$}

The voltage deviation is an indicator which shows the drop in the voltage at every bus from the nominal one, as shown in Eq. (8).

$$
f_{2}=\max \left|\frac{V_{i}-V_{\text {rated }}}{V_{\text {rated }}}\right|
$$

where $V_{\text {rated }}=1$ p.u. and $V_{i}$ is the voltage at bus number $i$ in p.u.

\section{- Annual cost $\left(f_{3}\right)$}

Considering the cost of DG and DSTATCOM, the annual cost function is defined as Eq. (9). This annual cost includes annual energy operation cost, DG cost and DSTATCOM cost. The terms having DG and DSTATCOM costs include annual cost of installed devices considering purchase, installation, operation and maintenance costs.
Therefore, the third objective function can be expressed as Eq. (10).

$$
\begin{aligned}
& C=c_{1} T P_{T \text { loss }}+c_{2} \sum_{i=1}^{N_{\mathrm{DG}}} P_{\mathrm{DG}_{i}}+c_{3} \sum_{j=1}^{N_{\mathrm{DSTATCOM}}} Q_{\mathrm{DSTATCOM}_{j}} \\
& f_{3}=\frac{C}{C_{\text {base }}}
\end{aligned}
$$

where $P_{T \text { loss }}$ is the total active power loss in the system in $\mathrm{kW}$, $T$ is number of hours in a year, $P_{\mathrm{DG}}$ is installed DG active power in $\mathrm{kW}, Q_{\text {DSTATCOM }}$ is installed DSTATCOM reactive power in $\mathrm{kVar}, N_{\mathrm{DG}}$ is number of installed DGs, $N_{\text {DSTATCOM }}$ is number of installed DSTATCOMs, $c_{1}$ is the energy loss cost (\$/kW/year), $c_{2}$ is annual cost of DG in ( $\$ / \mathrm{kW} /$ year), $c_{3}$ is annual cost of DSTATCOM ( $\$ / \mathrm{kVar} /$ year $)$ and $C_{\text {base }}$ is the cost at the base case.

\subsubsection{Constraints}

The objective functions in the above equations are subjected to the DG capacity limit and the DSTATCOM capacity, voltage and thermal limits.

\section{- DG capacity limit}

$G_{\text {min }} \leq G_{\text {capacity }} \leq G_{\max }$

where: $G_{\min }$ and $G_{\max }$ are the minimum and the maximum capacity of the DG respectively, in $\mathrm{kW}$. In this study $G_{\max } \leq 2.5 \mathrm{MW}$ according to reference [7].

\section{- DSTATCOM capacity limit}

$D_{\text {min }} \leq D_{\text {capacity }} \leq D_{\max }$

where: $D_{\min }$ and $D_{\max }$ are the minimum and the maximum capacity of the DSTATCOM respectively, in kvar.

\section{- Voltage limit}

$V_{\min } \leq\left|V_{i}\right| \leq V_{\max }$

where: $V_{\min }$ and $V_{\max }$ are the minimum and maximum bus voltages respectively, in p.u.

\section{DE IMPLEMENTATION}

The key idea of the DE is to use vector differences (addition and subtraction of the agent vectors) for mutating the population vector, unlike the Genetic Algorithm which uses conventional methods for the operations of crossover and mutation of the solutions. The algorithm of the DE for finding the optimum capacity and place of single and multiple DGs and DSTATCOMs in the radial distribution system is shown below.

DE Algorithm:

Step 1: Input the data of the grid.

Step 2: Initialize DE parameters (population size, differential weight, crossover probability, and maximum iteration).

Step 3: Initialize the population. 
Step 4: Run the radial load flow and calculate the objective function.

Step 5: Sort the population.

Step 6: Keep the best.

Step 7: While the stopping criterion is not satisfied.

Step 8: For each agent $x$.

Step 9: Find the perturbation vector $\boldsymbol{U}$.

Step 10: Find the perturbed vector y through the crossover of $x$ and $\boldsymbol{U}$.

Step 11: Run the radial load flow and calculate the objective function.

Step 12: Change $x$ to $y$ if $y$ is better than $x$.

Step 13: End while.

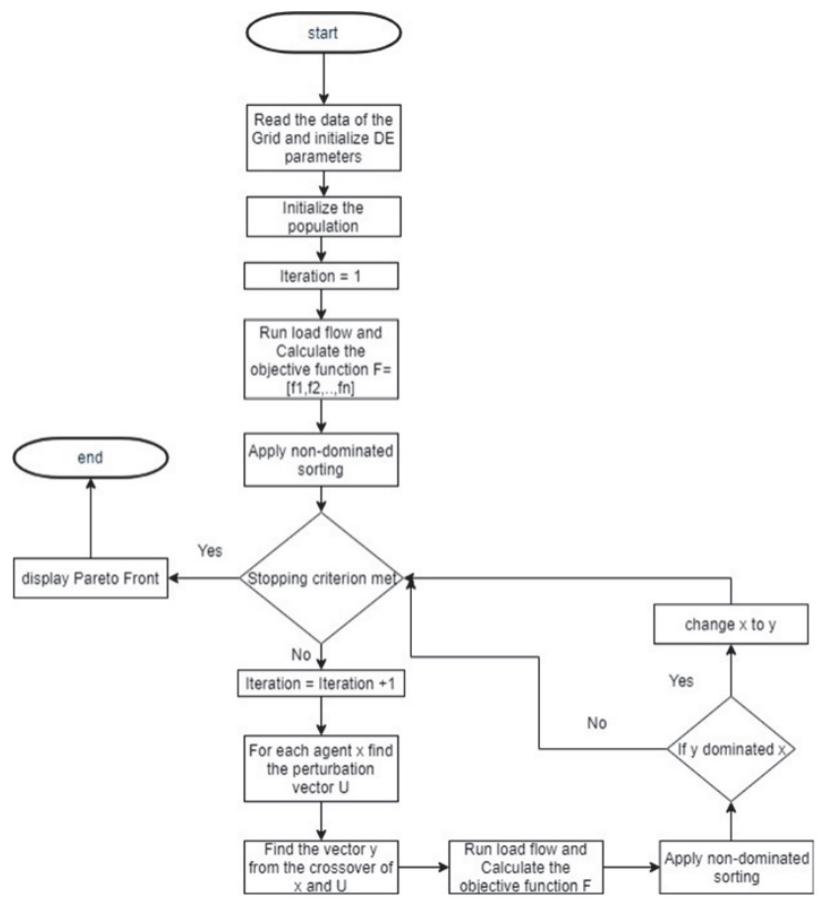

Figure 2 Flowchart of MODE

\section{MODE IMPLEMENTATION}

In this method, instead of having one optimum solution at the final stage of the optimization procedure, one can obtain the Tradeoff optimal solutions, which is known as Pareto solutions or the non-dominated solution. Here, the non-dominated term refers to the set of solutions which cannot be compared. Fig. 2 shows the flowchart of the MODE for finding the optimum capacity and place for single and multiple DGs and DSTATCOMs in the radial distribution grid.

\section{SIMULATION AND RESULTS}

In this paper, a constant power load model has been considered for modelling the behaviour of loads of the power system grid. The cost of DG-generated power and DSTATCOM has been neglected for this study. The energy loss cost of $\$ 0.05$ per unit has been taken for analysis of the cost-benefit (Shukla, T., et al. [18]). The DG and DSTATCOM annual costs are considered $3.5(\$ / \mathrm{kW})$ and 5.5 (\$/kVar), repectively.

Three case studies were performed as a single DG allocation, a single DSTATCOM allocation, a combination of a single DG and single DSTATCOM allocation and multiple DG and DSTATCOM allocation for active power loss reduction, voltage profile improvement, and the reduction of the annual cost. The proposed methods are tested on IEEE 33 bus system. This test system consists of 33 buses and 32 branches. The line and bus data are taken from [19]. This system fed on one side, and it has serially connected loads, while the load is assumed to be constant as shown in Fig. 3. The line voltage and real and reactive power loads of the radial distribution grid are $12.66 \mathrm{kV}$, 2.3219 MW and 1.4375 MVar respectively, while the base MVA is 100 MVA. Tab. 1 below shows the optimal parameters of DE and MODE after applying the trial and error method.

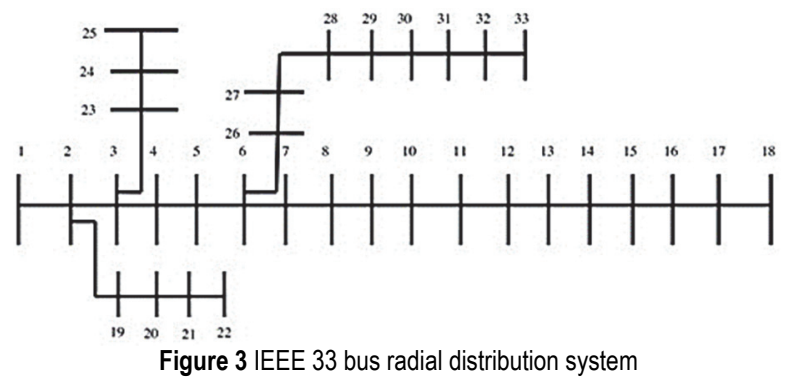

Table 1 Parameters of DE and MODE

\begin{tabular}{|l|c|c|}
\hline \multicolumn{1}{|c|}{ Parameters } & DE & MODE \\
\hline Population Size & 30 & 50 \\
\hline Max. Iteration & 30 & 30 \\
\hline Crossover Probability & 0.15 & 0.2 \\
\hline
\end{tabular}

\subsection{Single DG Allocation (Case 1)}

In this case, a single DG has been optimally placed into the network to improve its performance by using DE and MODE. To analyse the performance of each one of these algorithms, an IEEE 33 bus system was used. First, a simple load flow was performed. After that, the DG was optimally placed with the help of DE and MODE. Tab. 2 shows the real power losses, voltage deviation, annual energy cost, computation time, locations and size of the DG for DE, while Tab. 3 displays the results of the MODE.

Table 2 Network performance for a single DG allocation

\begin{tabular}{|l|c|c|}
\hline \multicolumn{1}{|c|}{ Performances } & Base & DE \\
\hline Power loss / kW & 210.9875 & 113.7027 \\
\hline Voltage deviation / p.u. & 0.096222 & 0.060792 \\
\hline Energy cost / \$ & 92412.55 & 59275.1 \\
\hline DG location & - & Bus 5 \\
\hline DG Size / kW & - & 2368.33 \\
\hline Comp. Time / sec & - & 17.28 \\
\hline Minimum voltage / p.u. & 0.90377 & 0.93921 \\
\hline Weighted vector & 1 & 0.59656 \\
\hline
\end{tabular}

Table 3 Pareto set of MODE (Single DG)

\begin{tabular}{|c|c|c|c|c|c|}
\hline \multicolumn{2}{|c|}{ DG } & \multirow{2}{*}{$\begin{array}{c}\text { Power loss } \\
\text { / kW }\end{array}$} & \multirow{2}{*}{$\begin{array}{c}\text { Voltage } \\
\text { deviation / p.u. }\end{array}$} & \multirow{2}{*}{$\begin{array}{l}\text { Annual } \\
\text { cost / \$ }\end{array}$} & \multirow[b]{2}{*}{$F$} \\
\hline $\begin{array}{l}\text { Bus } \\
\text { No. }\end{array}$ & $\begin{array}{c}\text { Size } \\
/ \mathrm{kW}\end{array}$ & & & & \\
\hline 8 & 2408 & 143.6 & 0.04877 & 72528.8 & 0.6319 \\
\hline 7 & 2176.8 & 121.9 & 0.05155 & 62099.4 & 0.5798 \\
\hline 7 & 1961.4 & 118.8 & 0.05449 & 59880 & 0.5813 \\
\hline 7 & 2015.2 & 119.4 & 0.05375 & 60358 & 0.5804 \\
\hline 6 & 2487.2 & 112.1 & 0.05605 & 59048.6 & 0.5733 \\
\hline 7 & 2290 & 124.5 & 0.05003 & 63691 & 0.5818 \\
\hline
\end{tabular}

From the results, it is clear that the minimum power loss, voltage deviation, and energy cost was obtained when MODE was used. The minimum CPU time was $11.47 \mathrm{sec}$ 
which was achieved when MODE was used. Fig. 4 shows the voltage profile, while Fig. 5 shows the Pareto front when MODE was used. Moreover, Fig. 6 shows the comparison between the results of DE and MODE in terms of the computation time and weighted vector results.
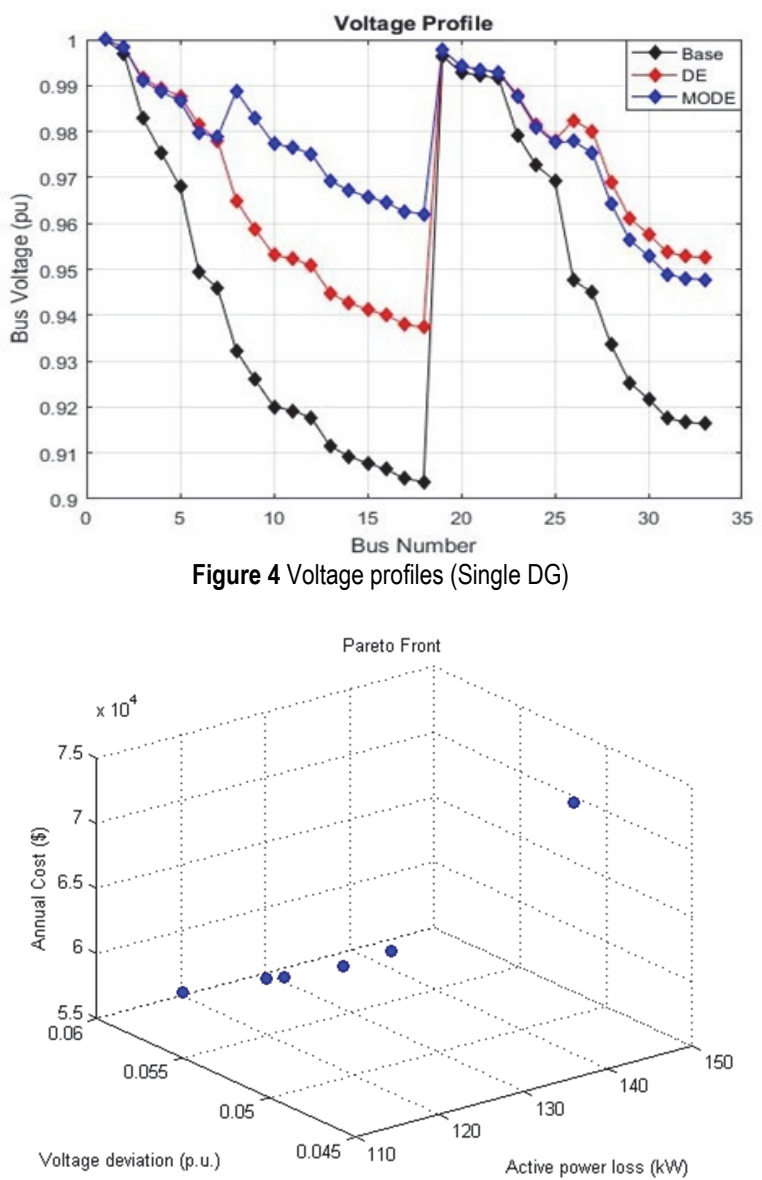

Figure 5 MODE Pareto Front (Single DG)

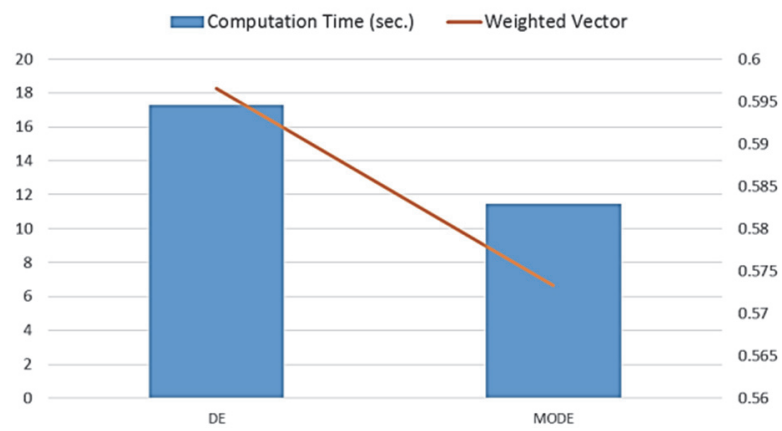

Figure 6 Comparison between DE and MODE for a single DG

\subsection{Single DSTATCOM Allocation (Case 2)}

In this case, a single DSTATCOM has been optimally placed into the network to improve its performance by using DE and MODE. To analyse the performance of each one of these algorithms, an IEEE 33 bus system is used. First, a simple load flow was performed. After that, the DG was optimally placed with the help of DE and MODE. Tab. 4 shows the real power losses, voltage deviation, annual cost, computation time, locations and size of the DSTATCOM for DE, while Tab. 5 displays the results of the MODE.
Table 4 Network performance for a single DSTATCOM allocation

\begin{tabular}{|l|c|c|}
\hline \multicolumn{1}{|c|}{ Performances } & Base & DE \\
\hline Power loss / kW & 210.9875 & 163.6385 \\
\hline Voltage deviation / p.u. & 0.096222 & 0.070222 \\
\hline Annual cost / \$ & 92412.55 & 79176.86 \\
\hline DSTATCOM location & - & Bus 6 \\
\hline DSTATCOM Size / kVar & - & 1875.8019 \\
\hline Comp. Time / sec & - & 17.41 \\
\hline Minimum voltage / p.u. & 0.90377 & 0.92977 \\
\hline Weighted vector & 1 & 0.7735 \\
\hline
\end{tabular}

Table 5 Pareto set of MODE (Single DSTATCOM)

\begin{tabular}{|c|c|c|c|c|c|}
\hline \multicolumn{2}{|c|}{ DSTATCOM } & \multirow[b]{2}{*}{$\begin{array}{c}\text { Power loss } \\
\text { / kW }\end{array}$} & \multirow[b]{2}{*}{$\begin{array}{c}\text { Voltage } \\
\text { deviation / p.u. }\end{array}$} & \multirow[b]{2}{*}{$\begin{array}{l}\text { Annual } \\
\text { cost } / \$\end{array}$} & \multirow[b]{2}{*}{$F$} \\
\hline $\begin{array}{l}\text { Bus } \\
\text { No. }\end{array}$ & $\begin{array}{l}\text { Size / } \\
\text { kVar }\end{array}$ & & & & \\
\hline 29 & 1384.1 & 151.9 & 0.08234 & 72068.6 & 0.7862 \\
\hline 28 & 1500.2 & 154.1 & 0.08131 & 73496.6 & 0.7892 \\
\hline 6 & 1706.3 & 163.2 & 0.07248 & 78306.8 & 0.7801 \\
\hline 8 & 1451.1 & 183.4 & 0.06997 & 86133.6 & 0.8249 \\
\hline 29 & 1715.8 & 158.6 & 0.07939 & 76330 & 0.7959 \\
\hline 7 & 1278.7 & 172.6 & 0.07132 & 80713.6 & 0.7983 \\
\hline 29 & 1782.1 & 160.8 & 0.07882 & 77558.8 & 0.8003 \\
\hline 8 & 1318.2 & 179.7 & 0.07111 & 83981.4 & 0.818 \\
\hline 8 & 1336.1 & 180.1 & 0.07095 & 84228.2 & 0.8187 \\
\hline
\end{tabular}

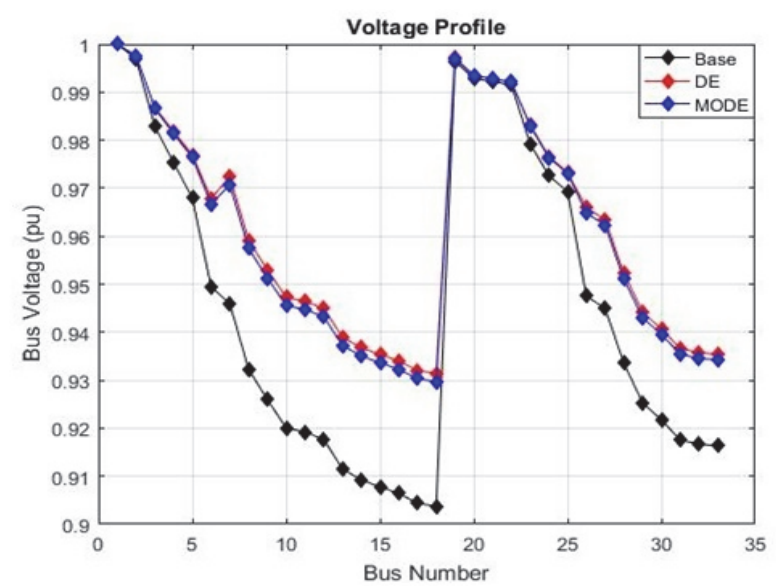

Figure 7 Voltage profiles (Single DSTATCOM)

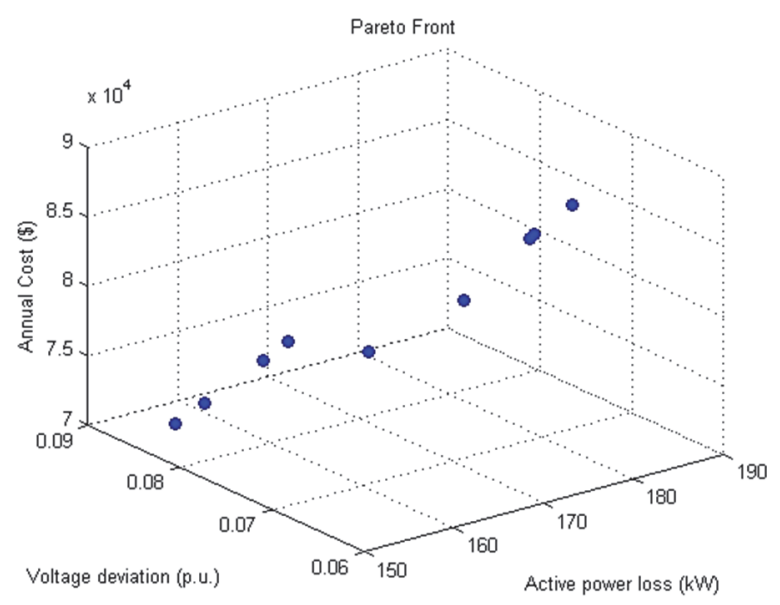

Figure 8 MODE Pareto Front (Single DSTATCOM)

From the results, it is clear that the minimum power loss and cost was obtained when MODE was used. The minimum CPU time was $14.63 \mathrm{sec}$ which was achieved when MODE was used. Fig. 7 shows the voltage profile, while Fig. 8 shows the Pareto front when MODE was used. Moreover, Fig. 9 shows the comparison between the results of DE and MODE in terms of the computation time and weighted vector results. 


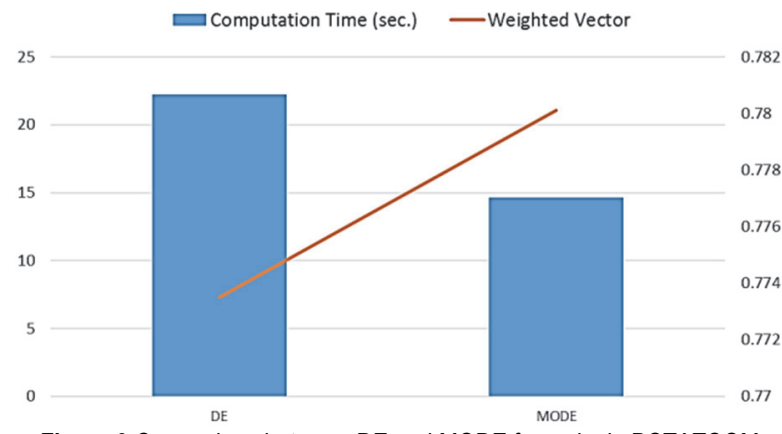

Figure 9 Comparison between DE and MODE for a single DSTATCOM

\subsection{Single DG and DSTATCOM Allocation (Case 3)}

In this case, a single DG and a DSTATCOM have been optimally placed into the network to improve its performance by using DE and MODE. To analyse the performance of each one of these algorithms, an IEEE 33 bus system was used. First, a simple load flow was performed. After that, the DG was optimally placed with the help of DE and MODE. Tab. 6 shows the real power losses, voltage deviation, annual energy cost, computation time, locations and size of the DG and DSTATCOM for DE, while Tab. 7 displays the results of the MODE.

Table 6 Network performance for a single DG and a DSTATCOM allocation

\begin{tabular}{|l|c|c|}
\hline \multicolumn{1}{|c|}{ Performances } & Base & DE \\
\hline Power loss / kW & 210.9875 & 80.4864 \\
\hline Voltage deviation / p.u. & 0.096222 & 0.033689 \\
\hline Annual cost / \$ & 92412.55 & 503.491 .476 \\
\hline DG location & - & Bus 7 \\
\hline DG Size / kW & - & 2327.5718 \\
\hline DSTATCOM location & - & Bus 26 \\
\hline DSTATCOM size / kVar & - & 1446.4543 \\
\hline Comp. Time / sec & - & 18.94 \\
\hline Minimum voltage / p.u. & 0.90377 & 0.96631 \\
\hline Weighted vector & 1 & 0.4016 \\
\hline
\end{tabular}

Table 7 Pareto Set of MODE (Single DG and a DSTATCOM)

\begin{tabular}{|c|c|c|c|c|c|}
\hline DG / kW & $\begin{array}{c}\text { DSTATCOM } \\
/ \mathrm{kVar}\end{array}$ & $\begin{array}{c}\text { Loss } / \\
\mathrm{kW}\end{array}$ & $\begin{array}{c}\text { Volt. devia. } \\
/ \text { p.u. }\end{array}$ & $\begin{array}{c}\text { Ann. } \\
\text { cost } / \$\end{array}$ & $F$ \\
\hline $\begin{array}{c}1871 \\
\text { (Bus 9) }\end{array}$ & $\begin{array}{c}2060 \\
\text { (Bus 31) }\end{array}$ & 117.9 & 0.0194 & 67390 & 0.4503 \\
\hline $\begin{array}{c}2425 \\
\text { (Bus 8) }\end{array}$ & $\begin{array}{c}1426 \\
\text { (Bus 27) }\end{array}$ & 79.16 & 0.0239 & 50076 & 0.3579 \\
\hline $\begin{array}{c}2447 \\
\text { (Bus 7) }\end{array}$ & $\begin{array}{c}1877 \\
\text { (Bus 12) }\end{array}$ & 169.4 & 0.0179 & 91484 & 0.5936 \\
\hline $\begin{array}{c}2390 \\
\text { (Bus 27) }\end{array}$ & $\begin{array}{c}1791 \\
\text { (Bus 29) }\end{array}$ & 68.03 & 0.0408 & 46521 & 0.3993 \\
\hline $\begin{array}{c}1541 \\
\text { (Bus 6) }\end{array}$ & $\begin{array}{c}2000 \\
\text { (Bus 29) }\end{array}$ & 88.89 & 0.0206 & 53098 & 0.3691 \\
\hline $\begin{array}{c}1871 \\
\text { Bus 10) }\end{array}$ & $\begin{array}{c}2060 \\
(31)\end{array}$ & 115.3 & 0.0194 & 66234 & 0.4429 \\
\hline
\end{tabular}

From the results, it is clear that the minimum power loss and cost was obtained when MODE was used. The minimum CPU time was $12.58 \mathrm{sec}$ which was achieved when MODE has used. Fig. 10 shows the voltage profile, while Fig. 11 shows the Pareto front when MODE was used. Moreover, Fig. 12 shows the comparison between the results of DE and MODE in terms of the computation time and weighted vector results.

To confirm the performance of the suggested algorithms on an IEEE33 bus radial distribution system, the results achieved were compared with previous work results like Genetic Algorithm [18], Immune Algorithm
[20], and Loss Sensitivity Method [21] and summarized in Tab. 8.

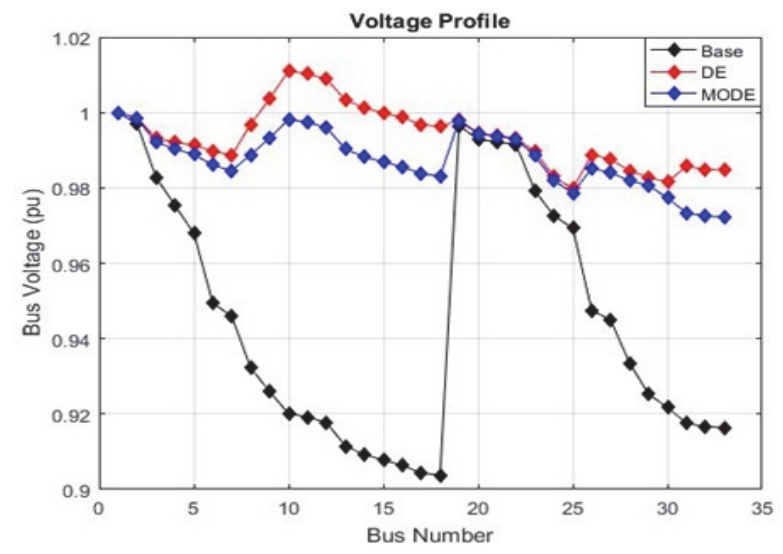

Figure 10 Voltage Profiles (Single DG and a Single DSTATCOM)

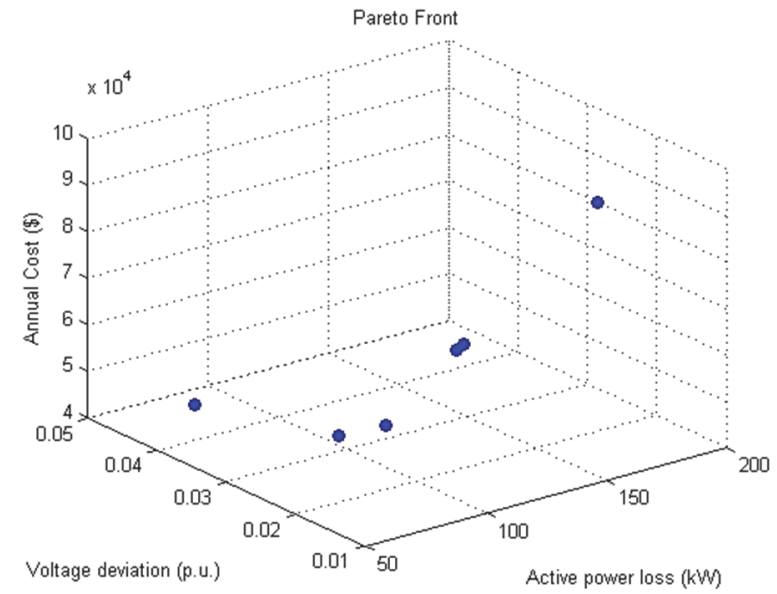

Figure 11 MODE Pareto Front (Single DG and a single DSTATCOM)

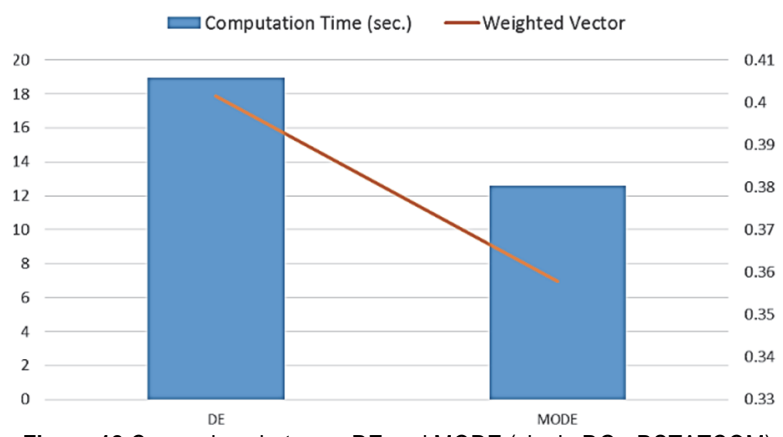

Figure 12 Comparison between DE and MODE (single DG - DSTATCOM)

\subsection{Multiple DG and DSTATCOM Allocation (Case 4)}

In this case, multiple DGs and DSTATCOMs have been optimally placed into the network to improve its performance by using DE and MODE. Optimal location and size of maximum three DGs and three DSTATCOMS, have been determined to achieve the same objectives. Tab.9 shows the work performance for multiple DG and DSTATCOM allocation. Power loss, voltage deviation, annual cost, weighted vector, minimum voltage and computation time by applying single and multi-objective methods are presented compared with the results of applying bacterial foraging optimization (BFO) algorithm in [16]. The proposed cost function is applied considering DG and DTATCOM costs. 
Table 8 Comparative Analysis

\begin{tabular}{|c|c|c|c|c|c|c|}
\hline Case & Performances & $\mathrm{DE}$ & MODE & $\begin{array}{c}\text { Genetic Algorithm } \\
{[18]} \\
\end{array}$ & $\begin{array}{c}\text { Immune Algorithm } \\
{[20]} \\
\end{array}$ & $\begin{array}{c}\text { Loss Sensitivity } \\
\text { Method [21] }\end{array}$ \\
\hline \multirow{5}{*}{ Single DG } & Base Loss / kW & 210.98 & 210.98 & 216 & 202 & 201 \\
\hline & Location & Bus 5 & Bus 6 & Bus 6 & - & Bus 30 \\
\hline & Size / kW & 2368.3 & 2487.2 & 2380 & - & 1000 \\
\hline & Active Loss / kW & 113.7 & 112.1 & 132 & - & 113 \\
\hline & Energy Saving / \$ & 42607 & 43309 & 36511 & - & - \\
\hline \multirow{5}{*}{ Single DSTATCOM } & Location & Bus 6 & Bus 6 & - & Bus 12 & Bus 30 \\
\hline & Size / kW & 1875.8 & 1706.3 & - & 962.49 & 3200 \\
\hline & Active Loss / kW & 163.64 & 163.2 & - & 171 & 198 \\
\hline & Minimum Voltage / p.u. & 0.931 & 0.93 & - & 0.925 & - \\
\hline & Time / sec & 17.41 & 11.47 & - & - & - \\
\hline \multirow{6}{*}{$\begin{array}{l}\text { Single DG and } \\
\text { DSTATCOM }\end{array}$} & DG Location & Bus 7 & Bus 8 & - & - & Bus 30 \\
\hline & DG Size / kW & 2327.5718 & 2425 & - & - & 1000 \\
\hline & DSTATCOM Location & Bus 26 & Bus 27 & - & - & Bus 30 \\
\hline & DSTATCOM Size / kVar & 1446 & 1426 & - & - & 1500 \\
\hline & Active Loss / kW & 80.49 & 79.16 & - & - & 86 \\
\hline & Minimum Voltage / p.u. & 0.98 & 0.972 & - & - & - \\
\hline
\end{tabular}

Table 9 Network performance for multiple DG and DSTATCOM allocation

\begin{tabular}{|c|c|c|c|c|c|c|c|c|}
\hline $\begin{array}{c}\text { Optimization } \\
\text { Algorithm }\end{array}$ & $\begin{array}{l}\mathrm{DG} \\
/ \mathrm{kW}\end{array}$ & $\begin{array}{c}\text { DSTATCOM / } \\
\text { kVar }\end{array}$ & $\begin{array}{c}\text { Power loss / } \\
\mathrm{kW}\end{array}$ & $\begin{array}{c}\text { Voltage } \\
\text { deviation / p.u. }\end{array}$ & $\begin{array}{c}\text { Annual cost } \\
/ \$\end{array}$ & $\begin{array}{l}\text { Weighted } \\
\text { vector }\end{array}$ & $\begin{array}{c}\text { Minimum } \\
\text { voltage / p.u. }\end{array}$ & $\begin{array}{c}\text { Comp. Time } \\
/ \text { sec }\end{array}$ \\
\hline DE & $\begin{array}{c}823 \text { (Bus 14) } \\
1002 \text { (Bus 25) } \\
1047 \text { (Bus 30) }\end{array}$ & $\begin{array}{c}444 \text { (Bus 12) } \\
516(\text { Bus 25) } \\
1089 \text { (Bus 30) }\end{array}$ & 13.67 & 0.0097 & 20603 & 0.1108 & 0.98721 & 22.63 \\
\hline MODE & $\begin{array}{c}1072 \text { (Bus 14) } \\
742 \text { (Bus 25) } \\
947 \text { (Bus 30) }\end{array}$ & $\begin{array}{c}521(\text { Bus 12) } \\
476(\text { Bus 25) } \\
1018 \text { (Bus 30) }\end{array}$ & 12.95 & 0.0089 & 20488 & 0.1059 & 0.99113 & 11.92 \\
\hline $\begin{array}{l}\text { Bacterial Foraging } \\
\text { Optimization [16] }\end{array}$ & $\begin{array}{l}850 \text { (Bus 12) } \\
750 \text { (Bus 25) } \\
860 \text { (Bus 30) } \\
\end{array}$ & $\begin{array}{l}400 \text { (Bus 12) } \\
350 \text { (Bus 25) } \\
850 \text { (Bus 30) }\end{array}$ & 15.07 & - & 22841 & - & 0.9862 & 12.96 \\
\hline
\end{tabular}

\section{CONCLUSION}

In conclusion, this research work demonstrated the formulation and implementation of the single-objective optimizer DE and the Pareto-frontier multi-objective optimizer MODE to help in reducing system real power losses, minimizing voltage deviation and reducing annual costs by allocating DG and DSTATCOM in the radial distribution system. As seen from the results, the best performance for the system was achieved when multiple DGs and DSTATCOMs were used. From the results, MODE proved to be better suited for this optimization as compared to DE and the other optimization algorithms such as Genetic algorithm (GA), Immune Algorithm (IA) and Bacterial Foraging Optimization (BFO). After using the MODE method to study the effects of DG and DSTATCOM allocation on power losses, voltage profile and cost, it was clear that system power losses and voltage deviation were reduced with the optimal allocation of the DG and DSTATCOM in the network, whereas, an unsuitable location or size of DG and DSTATCOM resulted in an increase in system power losses, voltage profile and cost.

\section{REFERENCES}

[1] Sirjani, R. \& Jordehi, A. R. (2017). Optimal placement and sizing of distribution static compensator (D-STATCOM) in electric distribution networks: Renewable and Sustainable Energy Reviews, 77, 688-694. https://doi.org/10.1016/j.rser.2017.04.035

[2] Gelenbe, E. \& Ceran, E. T. (2016). Energy packet networks with energy harvesting. IEEE Access, 4, 1321-1331. https://doi.org/10.1109/ACCESS.2016.2545340

[3] Ceran, E. T. \& Gelenbe, E. (2016). Energy packet model optimisation with approximate matrix inversion.
Proceedings of the $2^{\text {nd }}$ International Workshop on EnergyAware Simulation, 1-6. https://doi.org/10.1145/2939948.2939952

[4] Gelenbe, E. \& Ceran, E. T. (2015). Central or distributed energy storage for processors with energy harvesting. Sustainable Internet and ICT for Sustainability, 1-3. https://doi.org/10.1109/SustainIT.2015.7101380

[5] Gelenbe, E. \& Zhang, Y. (2019).Performance Optimization with Energy Packets. IEEE Systems Journal, 1-11. https://doi.org/10.1109/JSYST.2019.2912013

[6] Osman, I. H. \& Kelly, J. P. (1996). Meta-heuristics: an overview. Meta-heuristics. Springer, Boston, MA, 1-21. https://doi.org/10.1007/978-1-4613-1361-8_1

[7] Injeti, S. K. \& Kumar, N. P. (2013). A novel approach to identify optimal access point and capacity of multiple DGs in a small, medium and large scale radial distribution systems. International Journal of Electrical Power \& Energy Systems, 45(1), 142-151. https://doi.org/10.1016/j.jijepes.2012.08.043

[8] Sultana, S. \& Roy, P. K. (2014). Multi-objective quasioppositional teaching learning based optimization for optimal location of distributed generator in radial distribution systems. International Journal of Electrical Power \& Energy Systems, 63, 534-545. https://doi.org/10.1016/j.ijepes.2014.06.031

[9] Sultana, S. \& Roy, P. K. (2015). Oppositional krill herd algorithm for optimal location of distributed generator in radial distribution system. International Journal of Electrical Power \& Energy Systems, 73, 182-191. https://doi.org/10.1016/j.ijepes.2015.04.021

[10] Gupta, A. R. \& Kumar, A. (2015). Energy savings using DSTATCOM placement in radial distribution system. Procedia Computer Science, 70, 558-564. https://doi.org/10.1016/j.procs.2015.10.100

[11] Prabha, D. R. \& Jayabarathi, T. (2016). Optimal placement and sizing of multiple distributed generating units in distribution networks by invasive weed optimization algorithm. Ain Shams Engineering Journal, 7(2), 683-694. https://doi.org/10.1016/j.asej.2015.05.014 
[12] Ali, E. S., Elazim, S. A., \& Abdelaziz, A. Y. (2017). Ant Lion Optimization Algorithm for optimal location and sizing of renewable distributed generations. Renewable Energy, 101, 1311-1324. https://doi.org/10.1016/j.renene.2016.09.023

[13] Biswas, P. P., Mallipeddi, R., Suganthan, P. N., \& Amaratunga, G. A. (2017). A multiobjective approach for optimal placement and sizing of distributed generators and capacitors in distribution network. Applied Soft Computing, 60, 268-280. https://doi.org/10.1016/j.asoc.2017.07.004

[14] Kumar, M., Nallagownden, P., \& Elamvazuthi, I. (2017). Optimal placement and sizing of distributed generators for voltage-dependent load model in radial distribution system. Renewable Energy Focus, 19, 23-37. https://doi.org/10.1016/j.ref.2017.05.003

[15] Sultana, U., Khairuddin, A. B., Mokhtar, A. S., Zareen, N., \& Sultana, B. (2016). Grey wolf optimizer based placement and sizing of multiple distributed generation in the distribution system. Energy, 111, 525-536. https://doi.org/10.1016/j.energy.2016.05.128

[16] Devabalaji, K. R. \& Ravi, K. (2016). Optimal size and siting of multiple DG and DSTATCOM in radial distribution system using bacterial foraging optimization algorithm. Ain Shams Engineering Journal, 7(3), 959-971. https://doi.org/10.1016/j.asej.2015.07.002

[17] Al-Mahroqi, Y., Metwally, I. A., Al-Hinai, A., \& Al-Badi, A. (2012). Reduction of power losses in distribution systems. World Academy of Science, Engineering and Technology, 6,498-505. Retrieved from https://waset.org/publications/ 2058/reduction-of-power-losses-in-distribution-systems

[18] Shukla, T. N., Singh, S. P., Srinivasarao, V., \& Naik, K. B. (2010). Optimal sizing of distributed generation placed on radial distribution systems. Electric power components and systems, 38(3), 260-274. https://doi.org/10.1080/15325000903273403

[19] Sanam, J., Ganguly, S., Panda, A. K., \& Hemanth, C. (2017). Optimization of Energy Loss Cost of Distribution Networks with the Optimal Placement and Sizing of DSTATCOM Using Differential Evolution Algorithm. Arabian Journal for Science and Engineering, 42(7), 2851-2865. https://doi.org/10.1007/s13369-017-2518-y

[20] Taher, S. A. \& Afsari, S. A. (2014). Optimal location and sizing of DSTATCOM in distribution systems by immune algorithm. International Journal of Electrical Power \& Energy Systems, 60, 34-44. https://doi.org/10.1016/j.jjepes.2014.02.020

[21] Iqbal, F., Khan, M. T., \& Siddiqui, A. S. (2017). Optimal placement of DG and DSTATCOM for loss reduction and voltage profile improvement. Alexandria Engineering Journal, 57(2), 755-765.

https://doi.org/10.1016/j.aej.2017.03.002

\section{Contact information:}

Khalid IBRAHIM, MSc

(Corresponding author)

Department of Electrical and Electronic Engineering,

Eastern Mediterranean University,

99628, Famagusta, North Cyprus, Mersin 10, Turkey

E-mail: khld1993@yahoo.com

Reza SIRJANI, Assoc. Prof. Dr.

Department of Electrical and Electronic Engineering,

Eastern Mediterranean University,

99628, Famagusta, North Cyprus, Mersin 10, Turkey

E-mail: reza.sirjani@emu.edu.tr

Hussain SHAREEF, Prof. Dr.

Department of Electrical Engineering,

United Arab Emirates University,

P.O. Box 15551, Al-Ain, UAE

E-mail: shareef@uaeu.ac.ae 